\title{
Influence of Stent Length on Peri-Procedural Myocardial Injury after Percutaneous Coronary Intervention
}

\author{
MRM Mandal, MA Rahman, MAK Akanda, M Ullah, N Kar \\ Department of Cardiology, National Institute of Cardiovascular Diseases, Dhaka.
}

\begin{abstract}
Key Wards:

Myocardial

Injury, Stent,

PCI.

Background: About one-third of all elective PCI procedures are associated with significant myocardial injury termed peri-procedural myocardial injury (PMI), which has been associated with increased subsequent mortality. The stent length is one of the factors that can predict procedure related Troponon I release.

Methods: This interventional study was carried out to evaluate the influence of stent length on periprocedural myocardial injury by measuring post procedural release of Troponin I after percutaneous coronary intervention. Patients with e"70\% stenosed single vessel disease undergoing percutaneous coronary intervention with single stent were considered. Exclusion criteria were pre-procedural elevation of cardiac Troponin I above the $99^{\text {th }}$ percentile of upper reference, severely ill patients. Total 90 consecutive patients were included. Among them 45 patients had d" $20 \mathrm{~mm}$ long stent (group A) and rest 45 patients had > $20 \mathrm{~mm}$ long stent (group B). Blood samples for Troponin I were collected before procedure and 12 hours after procedure.
\end{abstract}

Results: Baseline characteristics including age, sex, risk factor for ischaemic heart disease and clinical diagnoses were almost similar between the two groups. During procedure no complications concurred $93.3 \%$ patients in group $A$ and $68.9 \%$ patients in group $B(p<0.05)$. Post procedural Troponin I level in group $A$ was $0.47 \pm 0.54$ and in group $B$ was $0.99 \pm 1.09(p<0.05)$. The stent length and post procedural Troponin I level had moderate correlation $(r=0.41)(p<0.05)$. In hospital complications in two groups include persistent angina (6.7\% vs. $11.1 \%)$, new ischaemic episode $(0.0 \%$ vs. $4.4 \%)(p>0.05)$. There were no myocardial infarction, acute left ventricular failure, emergency $C A B G$, arrhythmia and death in both groups. Durations of hospital stay were significantly higher in group B then group $(4.53 \pm 0.63$ vs. $4.07 \pm$ $0.65, p<0.05)$.

Conclusion: The incidence of procedural myocardial injury and procedural complications are more in longer stent group. So limiting the stent length by spot-stenting the lesions rather than covering the entire vessel between lesions may reduce peri-procedural release of cTnI and improve post procedural prognosis.

(Cardiovasc. j. 2014; 6(2): 143-148)

\section{Introduction:}

By the year 2020, coronary heart disease will hold first place in the world health organization's list of leading causes of disability. Coronary artery diseases are one of the major challenges faced by cardiologists. ${ }^{1}$ The South Asian countries like India, Pakistan, Bangladesh, Srilanka and Nepal contribute the highest proportion of the burden of cardiovascular diseases (CVDs) compared to any other region globally. ${ }^{2}$ Three small scale population based studies showed average prevalence of ischaemic heart disease 6.5 per thousand population of Bangladesh. ${ }^{3}$

Percutaneous coronary intervention (PCI) has become the predominant procedure for coronary revascularization. ${ }^{4}$ About one-third of all elective PCI procedures are associated with significant myocardial injury termed peri-procedural myocardial injury (PCI), which has been associated with increased subsequent mortality. ${ }^{4}$ Herrmann in his review article, classified PMI into two types: type 1 (proximal type), which is in proximity to the target lesion of PCI and may be due to side branch occlusion (SBO) ${ }^{5}$ It has been reported in $12.5 \%-19 \%$ of cases in which a stent was placed across a major side branch $(>1$ $\mathrm{mm}) .{ }^{6}$ Type 2 (distal type) which is in the perfusion territory of the treated coronary artery. $50 \%$ to $75 \%$ of all the PMI is type 2 (distal type). The atherosclerotic plaque disruption and 
local vessel trauma are the predominant causes in the distal injury and possess occlusion potential of both epicardial vessels and myocardial microvascular levels. ${ }^{5}$

Other influencing factors include the branch relationship to parent vessel lesion, branch vessel size and balloon to artery ratio. ${ }^{7}$ The proposed mechanisms of side branch occlusion (SBO) include snow plough effect (plaque shift), thrombus formation, dissection of the dilated artery involving the take-off of the side branch, side branch spasm and plaque embolization. ${ }^{8}$ The joint ESC/ACCF/AHA/WHF task force universal definition of myocardial infarction 2012 recently defined PMI during PCI, as an elevation of serum biomarkers preferably cardiac troponin $5 \mathrm{x}$ upper reference limit (URL) of normal population after PCI. ${ }^{9}$ Limiting stent length by spot-stenting lesions rather than covering the entire vessel between lesions may reduce subsequent embolization and side branch occlusion, reducing peri-procedure c $\mathrm{TnI}$ release that impacts on prognosis. ${ }^{10}$ Considering all these facts, every effort has been made to evaluate effects of stent length in PMI after elective PCI.

\section{Materials and methods:}

This interventional study was conducted in department of Cardiology, National Institute of cardiovascular diseases (NICVD) from August 2010 to August 2011 for a period of one (01) year. Patients of any age of both sexes presented with single vessel disease (SVD) undergoing PCI in NICVD were included in this study. The study populations were divided into two groups according to the length of stents used in individual PCI. In group A patients were intervened with the stent length $<20 \mathrm{~mm}$ and in group B, patients were intervened with the stent length $\geq 20 \mathrm{~mm}$ stent length. Prior to the commencement of this study, the research protocol were approved by ethical review board of NICVD. Informed consent was taken from the respondents prior to interview.

Patients with preprocedural elevation Troponin I were excluded from the study. Meticulous history and detailed clinical examination were carried out and were recorded in pre designed data sheet. Troponin I value was measured by Immulite 1000 troponin I (Siemens medical solutions diagnostics, Los Angeles, USA) both in the morning, before the procedure and 24 hours after the procedure. The Troponin kit used had a cut off value of $1.0 \mathrm{ng} / \mathrm{ml}$ for diagnosis of MI. 12 lead resting ECG were done before sending the patient to cath laboratory and 1 hour after the procedure and next morning after the procedure and additionally if needed. PCI were carried out in an artery having $\geq 70 \%$ stenosis. Low molecular weight heparin (LMWH) was continued for 48 hours after the procedure. After following the procedure, the patient was brought to CCU for 24 hours and evaluated clinically and biochemically.

\section{Statistical methods:}

All data were recorded in data sheet and Statistical analysis was performed by using SPSS version 16.0. $P$ value $<0.05$ was considered as significant.

\section{Results:}

This interventional study was conducted in NICVD. 45 patients were in Group A $(\leq 20 \mathrm{~mm}$ the stent length) and 45 patients were in group B ( $>20 \mathrm{~mm}$ the stent length).

\section{Table-I}

Age distribution of the study population ( $n=90)$

\begin{tabular}{|c|c|c|c|c|c|}
\hline \multirow[t]{2}{*}{$\begin{array}{l}\text { Age } \\
\text { (years) }\end{array}$} & \multicolumn{2}{|c|}{$\begin{array}{l}\text { Group A } \\
(\mathrm{n}=45)\end{array}$} & \multicolumn{2}{|c|}{$\begin{array}{c}\text { Group B } \\
(\mathrm{n}=45)\end{array}$} & \multirow[t]{2}{*}{$\begin{array}{c}\mathrm{P} \\
\text { value }\end{array}$} \\
\hline & Number & $\%$ & Number & $\%$ & \\
\hline$<40$ & 2 & 4.4 & 2 & 4.4 & \\
\hline $41-49$ & 13 & 28.9 & 17 & 37.8 & \\
\hline $50-59$ & 22 & 48.9 & 18 & 40.0 & \\
\hline$\geq 60$ & 8 & 17.8 & 8 & 17.8 & \\
\hline $\begin{array}{l}\text { Mean } \pm \mathrm{SD} \\
\text { Range } \\
(\min -\max )\end{array}$ & \multicolumn{2}{|c|}{$\begin{array}{l}52.42 \pm 8.38 \\
\quad(34-70)\end{array}$} & \multicolumn{2}{|c|}{$\begin{array}{l}51.82 \pm 8.39 \\
\quad(38-70)\end{array}$} & $0.73^{\mathrm{ns}}$ \\
\hline
\end{tabular}

Table I showing,. Majority of the patients belonged to 50 - 59 years age in both groups, which were $22(48.9 \%) \& 18(40 \%)$ in group A and group B respectively. Mean age was $52.42 \pm$ 8.38 yrs \& $51.82 \pm 8.39$ yrs in group A \& B $(p>0.05$.

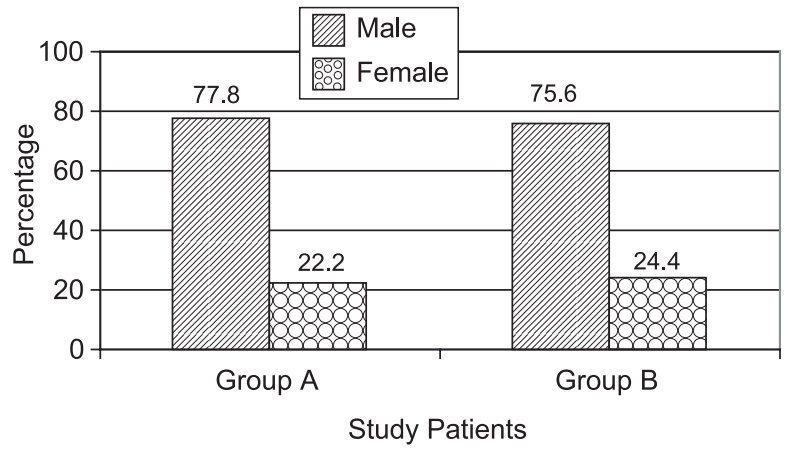

Fig.-1: Sex distribution among the study population by bar diagram $(n=90)$ 
In group A male patients was $77.8 \%$ and female was $22.2 \%$. In group B male was $75.6 \%$ and female $24.4 \%$. There was no significant difference in sex distribution (Fig 1).

Table-II:

Distribution of the study patients according to risk factors $(n=90)$.

\begin{tabular}{|c|c|c|c|c|c|}
\hline \multirow[t]{2}{*}{$\begin{array}{l}\text { Risk } \\
\text { factors }\end{array}$} & \multicolumn{2}{|c|}{$\begin{array}{c}\text { Group A } \\
(\mathrm{n}=45)\end{array}$} & \multicolumn{2}{|c|}{$\begin{array}{c}\text { Group B } \\
(\mathrm{n}=45)\end{array}$} & \multirow[t]{2}{*}{$\begin{array}{c}\mathrm{P} \\
\text { value }\end{array}$} \\
\hline & Number & $\%$ & Number & $\%$ & \\
\hline Smoking & 20 & 44.4 & 22 & 48.9 & $0.67^{\mathrm{ns}}$ \\
\hline Hypertensio & 30 & 66.7 & 28 & 62.2 & $0.66^{\mathrm{ns}}$ \\
\hline $\begin{array}{l}\text { Diabetes } \\
\text { mellitus }\end{array}$ & 30 & 66.7 & 28 & 62.2 & $0.66^{\mathrm{ns}}$ \\
\hline Dyslipidemia & 16 & 35.6 & 8 & 17.8 & $0.06^{\mathrm{ns}}$ \\
\hline Family h/o c & cad 3 & 6.7 & 3 & 6.7 & $1.00^{\mathrm{ns}}$ \\
\hline
\end{tabular}

Table II is showing prevalence of risk factors of coronary artery disease in group A \& B. Smoking was $20(44.4 \%)$ vs. $22(48.9 \%)$ ( $>00.05)$. Hypertension was $30(66.7 \%)$ vs. $(62.2 \%)(\mathrm{p}>0.05)$. Diabetes mellitus was also distributed like hypertension. Dyslipidemia was $16(35.6 \%)$ vs. $8(17.8 \%)$ ( $>00.05)$. Family history of CAD were found identical and statistically insignificant $(p>0.05)$.

\section{Table-III}

Study population according to preprocedural diagnosis $(n=90)$

\begin{tabular}{|c|c|c|c|c|c|}
\hline \multirow[t]{2}{*}{$\begin{array}{l}\text { Preprocedural } \\
\text { diagnosis }\end{array}$} & \multicolumn{2}{|c|}{$\begin{array}{l}\text { Group A } \\
(\mathrm{n}=45)\end{array}$} & \multicolumn{2}{|c|}{$\begin{array}{l}\text { Group B } \\
(\mathrm{n}=45)\end{array}$} & \multirow[t]{2}{*}{$\begin{array}{c}\mathrm{P} \\
\text { value }\end{array}$} \\
\hline & Number & $\%$ & Number & $\%$ & \\
\hline$\overline{\mathrm{CSA}}$ & 6 & 13.3 & 7 & 16.3 & \multirow[t]{5}{*}{$0.55^{\mathrm{ns}}$} \\
\hline UA & 10 & 22.2 & 9 & 20.9 & \\
\hline OMI( anterior) & r) 14 & 31.1 & 15 & 33.3 & \\
\hline OMI( inferior) & 13 & 28.8 & 11 & 24.4 & \\
\hline OMI(lateral) & 2 & 4.4 & 3 & 6.6 & \\
\hline
\end{tabular}

Table III showing in group A \& B, CSA was $13.3 \%$ vs. $20.9 \%$, UA was $22.2 \%$ vs. cases, OMI anterior was $31.1 \%$ vs. $33.3 \%$, OMI inferior was $28.8 \%$ vs. $24.4 \%$, OMI lateral was $4.4 \%$ vs. $4.4 \%$. No significant difference was observed between the groups ( $\mathrm{p}>0.05)$.

Table-IV

study population according to vessel involvement $(n=90)$.

\begin{tabular}{lcccccc}
\hline Vessel & \multicolumn{2}{c}{$\begin{array}{c}\text { Group A } \\
(\mathrm{n}=45)\end{array}$} & & \multicolumn{2}{c}{$\begin{array}{c}\text { Group B } \\
(\mathrm{n}=45)\end{array}$} & $\begin{array}{c}\text { P } \\
\text { value }\end{array}$ \\
\cline { 2 - 3 } & Number & $\%$ & & Number & $\%$ & \\
\hline LAD & 23 & 51.1 & 30 & 67.7 & $0.31^{\text {ns }}$ \\
RCA & 17 & 37.8 & & 11 & 24.4 & \\
LCX & 5 & 11.1 & & 4 & 8.9 & \\
\hline
\end{tabular}

In group A \& B LAD was 23 (51.1\%) vs.30 (67.7\%), RCA was 17 (37.8\%) vs. 11(24.4\%) and LCX was $5(11.1 \%) 4(8.9 \%)$ patients ( $>00.05)$ (Table IV).

Table-V

site of lesion in coronary arteries between two groups $(n=90)$

\begin{tabular}{lccccc}
\hline Site of & \multicolumn{2}{c}{ Group A } & & \multicolumn{2}{c}{ Group B } \\
\cline { 2 - 3 } \cline { 5 - 6 } lesion & \multicolumn{2}{c}{$(\mathrm{n}=45)$} & & \multicolumn{2}{c}{$(\mathrm{n}=45)$} \\
& Number & $\%$ & & Number & $\%$ \\
\hline Proximal segment & 9 & 20.0 & & 26 & 57.8 \\
Mid segment & 26 & 57.8 & & 19 & 42.2 \\
Distal segment & 10 & 22.2 & & 0 & 0.0 \\
\hline
\end{tabular}

Table V showing in group A \& B the site of lesions were proximal $9(20.0 \%)$ vs.26 (57.8\%), Mid $26(57.8 \%)$ vs.19 (42.2\%) and distal 10 $(22.2 \%)$ vs. $0(0 \%)$.

\section{Table-VI}

Study population according to procedural variables $(n=90)$.

\begin{tabular}{lcccc}
\hline Parameter & & $\begin{array}{c}\text { Group A } \\
(\mathrm{n}=45)\end{array}$ & $\begin{array}{c}\text { Group B } \\
(\mathrm{n}=45)\end{array}$ & P value \\
\hline Length of & LAD & $14.86 \pm 2.58$ & $29.73 \pm 4.05$ & $0.01^{\mathrm{s}}$ \\
stent (mm) & LCX & $14.88 \pm 2.57$ & $26.18 \pm 4.35$ & \\
& RCA & $13.00 \pm 3.87$ & $30.00 \pm 7.11$ & \\
Diameter of & LAD & $3.15 \pm 0.39$ & $2.90 \pm 0.24$ & $0.56^{\mathrm{ns}}$ \\
stent (mm) & LCX & $3.08 \pm 0.39$ & $2.97 \pm 0.21$ & \\
& RCA & $3.15 \pm 0.33$ & $3.00 \pm 0.00$ & \\
Inflation & LAD & $11.73 \pm 2.11$ & $13.83 \pm 1.26$ & $0.16^{\mathrm{ns}}$ \\
pressure (atm) & LCX & $12.05 \pm 1.39$ & $13.09 \pm 1.45$ & \\
& RCA & $11.60 \pm 1.67$ & $14.00 \pm 1.63$ & \\
Duration of & LAD & $21.04 \pm 1.94$ & $27.03 \pm 3.45$ & $0.07^{\mathrm{ns}}$ \\
inflation & LCX & $21.88 \pm 2.36$ & $25.90 \pm 3.61$ & \\
(seconds) & RCA & $21.00 \pm 2.23$ & $25.25 \pm 4.11$ & \\
\hline
\end{tabular}

Table VI is showing the distribution of the study population according to procedural variables. The mean length of several lesions were higher in group B than that of group A with significant statistical difference $(\mathrm{p}<0.05)$. The diameter of stent, inflation pressure and duration of inflation were almost identical in group A and group B with no statistical difference $(\mathrm{p}>0.05)$.

\section{Table-VII}

post procedural troponin $i$ level between two groups. $(n=90)$

\begin{tabular}{lccc}
\hline Troponin i(ng/ml) & $\begin{array}{c}\text { Group A } \\
(\mathrm{n}=45)\end{array}$ & $\begin{array}{c}\text { Group B } \\
(\mathrm{n}=45)\end{array}$ & P value \\
\hline Post procedural & $0.47 \pm 0.54$ & $0.99 \pm 1.09$ & $0.006^{\mathrm{s}}$ \\
Range (min-max) & $(0.20-3.66)$ & $(0.20-4.72)$ & \\
\hline
\end{tabular}


Post procedural troponin-I level was significantly higher in group B than group A of the study patients $(\mathrm{p}<0.05)$ (Table VII).

\section{Table-VIII}

Study population according to procedural complications $(n=90)$.

\begin{tabular}{lcccccc}
\hline $\begin{array}{l}\text { Procedural } \\
\text { complications }\end{array}$ & \multicolumn{2}{c}{$\begin{array}{c}\text { Group A } \\
(\mathrm{n}=45)\end{array}$} & & \multicolumn{2}{c}{$\begin{array}{c}\text { Group B } \\
(\mathrm{n}=45)\end{array}$} & $\begin{array}{c}\text { P } \\
\text { value }\end{array}$ \\
\cline { 2 - 3 } & Number & $\%$ & & Number & $\%$ & \\
\hline None & 42 & 93.3 & & 31 & 68.9 & $0.01^{\mathrm{s}}$ \\
Intimal dissection & 0 & & 0.0 & 3 & 6.7 \\
$\begin{array}{l}\text { Side branch } \\
\text { occlusion }\end{array}$ & 1 & 2.2 & & 9 & 20.0 & \\
Slow flow & 2 & 4.4 & & 2 & 4.4 & \\
\hline
\end{tabular}

Procedural complications were significantly higher in group B $(\mathrm{p}<0.05)$ (Table VIII). Side branch occlusion was $9(20 \%)$ vs $1(2.2 \%)$., slow flow $2(4.4 \%)$ vs. $2(4.4 \%)$, intimal dissection $3(6.7 \%)$ vs 0 .

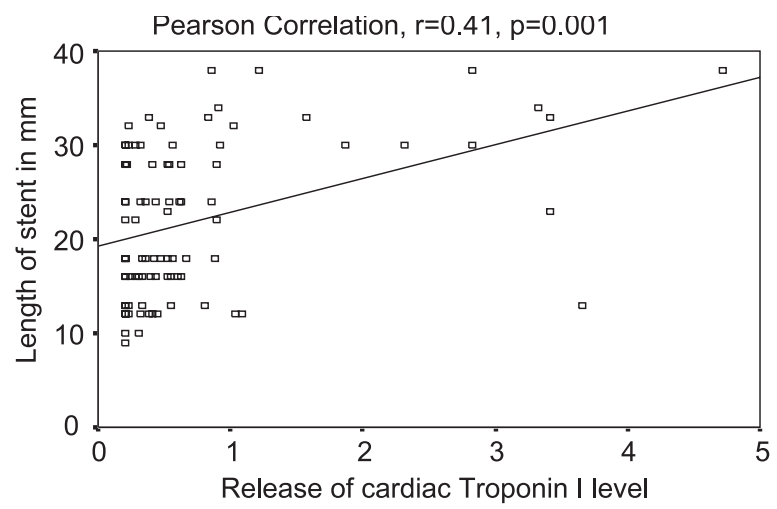

Fig.-2. Correlation between length of stent and release of cardiac troponin I level

The figure II showing that there was a moderate positive correlation between length of stent and release of cardiac troponin I level $(r=0.41)$, $(p<0.05)$.

\section{Discussion:}

Distribution of the patients by age showed majority were in the age group of 50-59 years in both group A (48.9\%) and group B (40.0\%). Mean $\pm \mathrm{SD}$ were $52.42 \pm 8.38$ and $51.82 \pm 8.39$ years in group A \& B respectively, ( $>0.05)$. Ali et al. (2006) mentioned mean age of his study population was $52.59 \pm 6.65$ years $^{9}$ and Stephen et al. found mean age of this study population $62.2 \pm 10$ years. $^{10}$
Sex distribution in this study showed that, male in group A \& B was 35 (77.8\%) \& $34(75.6 \%)$ and female were $10(22.2 \%) \& 11(24.4 \%)$. The differences were statistically insignificant $(p>0.05)$. Similar result was reported by Milner et al, where male patients were $70.23 \%$ and female patients were $29.77 \%{ }^{11}$

Risk factors between two groups were compared in this study. In both groups the major risk factors were smoking, hypertension, diabetes mellitus, dyslipidaemia and family history of coronary artery disease. In group A \& B smoking was $20(44.4 \%)$ vs. $22(48.9 \%) \quad(p>0.05)$. Hypertension was 30 (66.7\%) vs. $(62.2 \%)$ $(p>0.05)$. Diabetes mellitus was also distributed like hypertension. Dyslipidemia was 16 (35.6\%) vs. $8(17.8 \%) \quad(p>0.05)$. Family history of CAD was found identical and statistically insignificant $(p>0.05)$. Roy has done the similar study and found that smoking, hypertension, diabetes mellitus, dyslipidaemia and family history of coronary artery disease were major risk factors. ${ }^{12}$

Regarding preprocedural diagnosis in group A $\&$ B, Chronic stable angina was $13.3 \%$ vs. $16.3 \%$, Unstable angina was $22.2 \%$ vs. $20.9 \%$ cases. $31.1 \%$ vs. $33.3 \%$ had OMI anterior, $28.8 \%$ vs. $24.4 \%$ had OMI inferior and $4.4 \%$ vs $6.6 \%$ had OMI lateral ( $p>0.05)$. Uddin et al found similar preprocedural diagnosis of similar with this study. ${ }^{13}$

In group A \& B, involved vessels were LAD 23 (51.1\%) vs.30 (67.7\%), RCA $17(37.8 \%)$ vs. 11 $(24.4 \%)$ \& LCX 5 (11.1\%) vs. $4(8.9 \%)$ (p>0.05) in Group A and B. Bonnelo et al in their study found LAD as commonest target vessel (46\% vs. $50 \%)$ followed by RCA ( $24 \%$ vs. $16 \%$ ) and LCX (20\% vs. $30 \%$ ), which was similar with this study. ${ }^{14}$

The distribution of study population according to site of lesion in coronary arteries shows that, in group A \& B the site of lesions were proximal in $9(20.0 \%)$ vs. $26(57.8 \%)$, mid in $26(57.8 \%)$ vs. $19(42.2 \%)$ \& distal in $10(22.2 \%)$ vs. $0 \%$. Uddin et al had similar lesion distribution in coronary arteries in a similar study. ${ }^{13}$

The mean length of stents in group A \& B were found $14.86 \pm 2.58 \mathrm{~mm} \& 29.73 \pm 0.5 \mathrm{~mm}$ in $\mathrm{LAD}$, $14.88 \pm 2.57 \mathrm{~mm} \& 26.18 \pm 4.35 \mathrm{~mm}$ in LCX, 13.00 
$\pm 3.87 \mathrm{~mm} \& 30.00 \pm 7.11 \mathrm{~mm}$ in RCA. The difference was statistically significant $(p<0.05)$. The diameter of stent in group A \& B were found $3.15 \pm 0.39 \mathrm{~mm} \& 2.09 \pm 0.24 \mathrm{~mm}$ in $\mathrm{LAD}, 3.08 \pm$ $0.39 \mathrm{~mm} \& 2.97 \pm 0.21 \mathrm{~mm}$ in LCX, $3.15 \pm 0.33$ $\mathrm{mm} \& 3.00 \pm 0.00 \mathrm{~mm}$ in RCA.

The post procedural troponin I in group A \& B is $0.47 \pm 0.54 \& 0.99 \pm 1.09 \mathrm{ng} / \mathrm{ml}$ respectively $(p<0.05)$. Similar result was found by Shaha. ${ }^{15}$ They mentioned that, in patients demonstrating PCI, postprocedural elevation in troponin I had evidence of new irreversible myocardial injury. Ricchiuti et al mentioned that cardiac troponin I is more specific for the detection of myocardial injury after PCI. ${ }^{16}$

Correlation between length of stent and release of cardiac troponin I was analyzed in this study by pearson correlation t-test. There was moderate positive correlation $(\mathrm{r}=0.404)$. Hoole et al showed that troponin I release after elective PCI was predominantly related to stent length. ${ }^{17}$

In group A \& B, procedural complications was found in $6.7 \%$ vs. $31.1 \%$ cases, side branch occlusion in $2.2 \%$ vs. $20.0 \%$ cases, slow flow in $4.4 \%$ vs. $4.4 \%$ cases $(p<0.05)$. Shaha found intimal dissection in $4.0 \%$ cases, side branch occlusion in $8.0 \%$ cases, slow flow in $6.0 \%$ cases. ${ }^{15}$ Califf et al found a similar result as procedural complications and explained that such events occurred due to distal embolisation, side-branch occlusion, coronary dissection and disruption of collateral ûow. ${ }^{18}$

\section{Conclusion:}

From this study it may be concluded that the incidence of procedural myocardial injury and procedural complications were more in longer stent group. Limiting stent length by spotstenting lesions rather than covering the entire vessel between lesions may reduce subsequent embolization and side branch occlusion, reducing peri-procedure cTnI release that impacts on prognosis.

\section{Study Limitations}

There were some limitations in this study. Sample size taken in this study was small and it was a non randomized sampling method.

\section{Recommendation}

For further study, the following recommendations are proposed: A large scale randomized study should be done to evaluate the actual scenario. Limiting stent length by spot-stenting lesions rather than covering the entire vessel between lesions may reduce subsequent embolization and side branch occlusion, reducing peri-procedure c $\mathrm{TnI}$ release that impacts on prognosis.

Conflict of Interest - None.

\section{References:}

1. Islam AKMM, Ali M , Haque SA, et al. Aziz M. Inhospital outcome after percutaneous coronary intervention (PCI) in patients with low haemoglobin level. Cardiovasc.J 2009; 2(1): 55-60.

2. Reddy KS, Yusuf S. Emerging epidemic of cardiovascular disease in developing countries. Circulation 1998; 97: 596-601.

3. Islam MS, Majumdar AAS, Rahman S, et al. Influences of ballon and stent on initial success, acute complications and restenosis after percutaneous trnsluminal coronary angioplasty. Bangladesh Heart Journal 2003; 18(1):21-28.

4. Babu GJ, Walker M, Dere KM, Yellon DJ, Girish H, Babu G. Peri-procedural myocardial injury during percutaneous coronary intervention: an important target for cardioprotection. Eur Heart J 2010; 10:1093.

5. Herrmann J. Peri-procedural myocardial injury: 2005 update. Eur Heart J 2005; 26: 2493-2519.

6. Aliabadi D, Tilli FV, Bowers TR, et al. Incidence and angiographic predictors of side branch occlusion following high-pressure intracoronary stenting. Am J Cardiol 1997; 80: 994-997.

7. Poerner TC, Kralev S, Voelker W, et al. Natural history of small and medium sized side branches after coronary stent implantation. Am Heart J 2002; 143: 627-635.

8. Arora RR, Raymond RE, Dimas AP, Bhadwar K, Simpfendorfer C. Side branch occlusion during coronary angioplasty: incidence, angiographic characteristics and outcome. Catheter Cardiovasc Diagn 1989; 18: 210-212.

9. Thygesen K, Alpert JS, White HD. Universal deûnition of myocardial infarction. Euro Heart J 2012; 33: 2551-2567.

10. Ali M, Reza AS, Jamaluddin M, et al. In-hospital Outcome of 500 Cases of Percutaneous Coronary Intervention. Bangladesh Heart Journal 2006; 21(1): 29-34.

11. Hoole SP, Heck PM, Sharples L, Dutka DP, West NEJ. Coronary stent length predicts PCI-induced cardiac myonecrosis. Coronary Artery Disease 2010; 21:312-317.

12. Miller WL, Garratt KN, Burrit MF, Reeder GS, Jaffe AS. Timing of peak troponin- $\mathrm{T}$ and creatine kinase-MB 
elevations after percutaneous coronary intervention. Chest 2004; $125: 275-280$.

13. Roy D. Effect of trimetazidine pre-treatment on the reduction of peri-procedural myocardial injury after elective percutaneous coronary intervention (PCI), MD Thesis, National Institute of Cardiovascular Diseases, Dhaka. 2010.

14. Uddin MS, Khalequzzaman M, Chowdhury AHK, et al. Coronary Angioplasty with stent-alone Technique in Hospital Outcome. Bangladesh Heart Journal 2009; 24(1): 16-20.

15. Bonello L, Sbragia P, Amabile A, et al. Protective effect of an acute oral loading dose of trimetazidine on myocardial injury following percutaneous coronary intervention. Heart 2007; 93: 703-707.

16. Shaha CK. Reduction of peri-procedural myocardial injury and infarction by loading dose of atorvastatin during elective percutaneous coronary intervention (PCI). MD Thesis, National Institute of Cardiovascular Diseases, Dhaka. 2011.

17. Ricchiuti V, Shear WS, Henry TD, Paulsen PR, Miller EA, Apple FS. Monitoring plasma cardiac troponin I for the detection of myocardial injury after percutaneous transluminal coronary angioplasty. Clinica Chimica Acta 2000; 302: 161-170.

18. Hoole SP, Heck PM, Sharples L, Dutka DP. Coronary stent length predicts PCI-induced cardiac myonecrosis. Coronary Artery Disease. N Eng J Med 2010; 21(5): 312-317. 